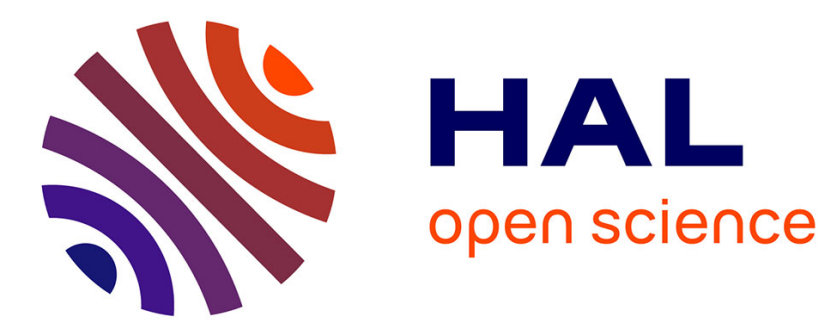

\title{
EFFECT OF PULSE SHAPING ON INTERACTION PROCESSES IN LASER PRODUCED PLASMAS
}

\author{
François Amiranoff, R. Fabbro, E. Fabre, C. Garban, J. Virmont
}

\section{To cite this version:}

François Amiranoff, R. Fabbro, E. Fabre, C. Garban, J. Virmont. EFFECT OF PULSE SHAPING ON INTERACTION PROCESSES IN LASER PRODUCED PLASMAS. Journal de Physique Colloques, 1979, 40 (C7), pp.C7-729-C7-730. 10.1051/jphyscol:19797352 . jpa-00219347

\section{HAL Id: jpa-00219347 https://hal.science/jpa-00219347}

Submitted on 1 Jan 1979

HAL is a multi-disciplinary open access archive for the deposit and dissemination of scientific research documents, whether they are published or not. The documents may come from teaching and research institutions in France or abroad, or from public or private research centers.
L'archive ouverte pluridisciplinaire HAL, est destinée au dépôt et à la diffusion de documents scientifiques de niveau recherche, publiés ou non, émanant des établissements d'enseignement et de recherche français ou étrangers, des laboratoires publics ou privés. 


\title{
EFFECT OF PULSE SHAPING ON INTERACTION PROCESSES IN LASER PRODUCED PLASMAS
}

\author{
F. Amiranoff, R. Fabbro, E. Fabre, C. Garban and J. Virmont. \\ Laboratoire de Physique des Milieux Ionisés, Ecole Polytechnique, 91128 Palaiseau Cedex, France.
}

In order to understand the effect of long shaped pulses which must be used to reach the ablative compression mode in laser fusion experiments, we have set an experiment in which we have studied the effect of the prepulse shape, added to the main pulse, on the interaction processes, and particularly on the stimulated Brillouin backscattering and on the generation of hot electrons.

The experiments were made with a Neodymium giass laser which delivers pulses of 100 Giv peak power with a duration of 100 ps FWHM. A pulse staker permits to generate two types of pulse shape : type $I$ is a single 100 ps pulse leading the main pulse by 500 ps and containing $10 \%$ or $30 \%$ of the main pulse energy, the type II is a 500 ps plateau like prepulse in front of the main pulse and containing $30 \%$ of its energy. Beam was focused on flat aluminium targets at intensities of $2.10^{15} \mathrm{~W} / \mathrm{cm}^{2}$.

The diagnostics are the following : optical energy balance is measured with an UIbricht sphere; backreflection is also monitored. The spectroscopy of the specularly reflected light has been made in some experiments in the case of a 22,5 oblique$1 y$ incident beam. The continuous $X$ ray emission has been analysed with a 9 channels system using the absorber foil method. Change collectors protected from secondary emission were used to study the fast and thermal ion emission.
The major results are given in Table I for backscattering and optical energy balance; we observe that the backscattering is effectively increased by the prepulse, mostly in the case of the discrete prepulse, but it always remains lower than $20 \%$. The absorption is surprisingly constant. The figure 1 shows the effect of prepulse on fast ions and hard $X$ rays emissions. From these results and electron temperature measurements we have also concluded that : soft $X$ ray emission and thermal ion production are increased; hard $X$ ray emission, fast ions, and $T_{H}$ hot electron temperature are decreased, depending somehow on the pulse structure.

The figure 2 shows an example of the spectra of the specularly reflected light in the case of the $22^{\circ} 5$ obliquely incidence, obtained in different experimental conditions. It appears that the spectrum is blue shifted without prepulse, is unshifted with the continuous prepulse, red shifted and very broad with the disc te prepulse.

The experimental results have been analysed by comparison with the data obtained from a ID Lagrangian numerical simulation. Figure 3 gives the electron density profiles for the time corresponding to the maximum of the main pulse. It appears that the prepulse introduces strong modification in density profile. In the two cases of prepulse a gentle density gradient is generated in the underdense plasma at 0.6 to $0.8 n_{\mathrm{c}}$. 
This condition is very favorable for the Brillouin instability and thus can explain the increased of the backreflection. It is interesting to note that the total level of scattered light is almost independant of pulse structure. This seems to indicate that when the prepulse is present the scattering is only more collimated as one can expect for a less inhomogeneous plasma with more gentle electron density gradient.

Numerical determination of the phase velocity of the $0.85 n_{c}$ surface is in agreement with the observed general behaviour of the mean spectral shift of the specular reflection. The strong spectral broadening observed in the case of the discrete prepulse can be a signature of ion turbulence in the underdense plasma. Numerical simulation confirm the possible existence of this turbulence because of the presence of very steep temperature gradients associated to the density gradients shown on the fig.3.

The second point of interest concern the reduction of the effect of hot electrons production as observed by the reduction of hard $X$ ray and fast ion emission and the decrease of hot electron temperature. This is not clearly understood but however the smaller value of the hot electron temperature indicates that probably resonance absorption is less effective because of the longer density gradient. However, these larger density gradients will, in turn favour collisionnal absorption and maintain or even increase the fractionnal absorption as shown on table I.

In conclusion, prepulse affects significantly the interaction processes. It seems that density profile modification can explain the increase of Brillouin backscattering. Hard $X$ ray emission and consequently hot electrons production are decreased. This will be probably due to a reduction in reson- nant absorption and enhanced classical absorption. This work has been made as a part of the scientific program of the GRECO Interaction Laser Matter.

\begin{tabular}{|c|c|c|c|c|c|c|}
\hline $\begin{array}{l}\text { Pulse } \\
\text { shape }\end{array}$ & $B . S$ & $\begin{array}{l}0^{\circ} \\
A B b s .\end{array}$ & B.S. & $\begin{array}{l}22,5^{\circ} \\
A b s .\end{array}$ & ${ }^{A 1}$ & $\begin{array}{l}45^{\circ} \\
A B s .\end{array}$ \\
\hline & 142 & $40 \pi$ & $6 z$ & $35=$ & $42^{\circ}$ & $21:$ \\
\hline $30=\square$ & $20 z$ & 412 & 142 & 352 & 82 & 22: \\
\hline $302 \square$ & $17 z$ & $46 z$ & $11,5 z$ & $36 z$ & 62 & $20 z$ \\
\hline
\end{tabular}

Table I : Fraction of backscattered light : B.S. Total absorption : Abs.

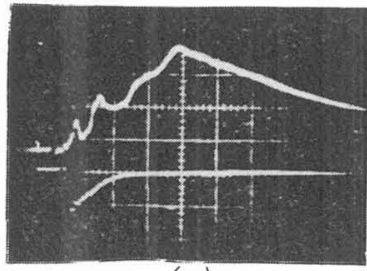

(a)

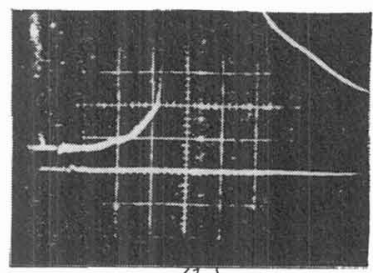

(b)
Figure 1 : Effect of a prepulse on ion (upper trace) and $X$ ray (30Kev) (lower trace). 200ns/div. a) without prepulse; b) with prepulse

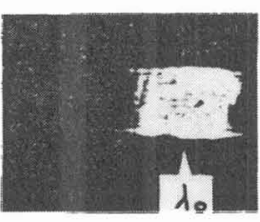

(a)

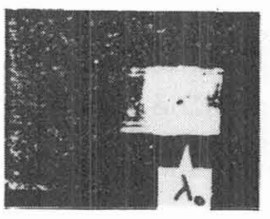

(b)

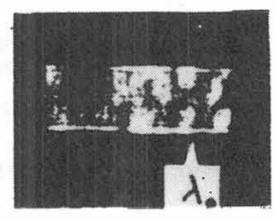

(c)
Figure 2 : Spectra of the specularly reflected light a) without prepulse; b) with continuous prepulse; c) with discrete prepulse.

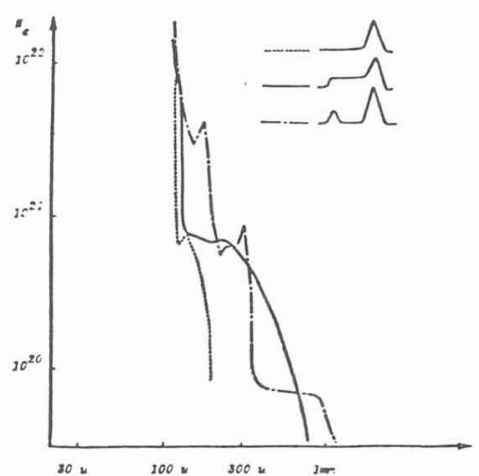

Figure 3 : electron density profiles. 